\title{
ESTÁGIO EM FILOSOFIA E PRÁTICAS DE EXPERIÊNCIA DE SI (DOCENTE)
}

\author{
Elisete M. Tomazetti*
}

Resumo: Este artigo apresenta algumas reflexões acerca das aulas de orientação do Estágio Curricular Supervisionado em Filosofia, com o intuito de pensar sobre os modos de produção de sujeitos professores e professoras de Filosofia que ali ocorrem. Foram analisados alguns projetos e relatórios de estágio, que tomados como dispositivos pedagógicos, conduzem os estudantes a estabelecer relações consigo mesmos - práticas de si (docente). Desta análise rastreamos dois acontecimentos: narrativas sobre formação em Filosofia e narrativas sobre tornar-se professor e professora de Filosofia. Os/As estudantes são conduzidos/as a pensar, a planejar e a atuar como professores e professoras no ensino médio; retomam seu percurso formativo; recuperam suas vivências, avaliam os conhecimentos adquiridos, as práticas de ensino vivenciadas e analisam a si mesmos. As análises realizadas estão sustentadas em alguns conceitos e ideias de Michel Foucault (1997, 2008, 2012) e Jorge Larrosa (1994).

Palavras-chave: Estágio em Filosofia; Dispositivo Pedagógico; Experiência de Si.

Resumen: Este artículo presenta algunas reflexiones sobre las clases de supervisión de la Pasantía Curricular Supervisada en Filosofía, con el fin de reflexionar sobre los modos de producción de los profesores y profesoras de Filosofía que se producen allí. Se analizaron algunos proyectos e informes de pasantías, que, tomados como dispositivos pedagógicos, llevan a los estudiantes a establecer relaciones con ellos mismos: auto-prácticas (profesor). A partir de este análisis, hacemos un seguimiento de dos eventos: narraciones sobre formación en filosofía y narrativas sobre cómo convertirse en profesor y profesor de filosofía. Los estudiantes son llevados a pensar, planificar y actuar como maestros en la escuela secundaria; reanudan su viaje formativo; recuperan sus experiencias, evalúan los conocimientos adquiridos, las prácticas docentes experimentadas y se analizan. Los análisis realizados se basan en algunos conceptos e ideas de Michel Foucault (1997, 2008, 2012) y Jorge Larrosa (1994).

Palabras claves: Pasantía de Filosofía; Dispositivo pedagógico; Experiencia de Si.

\section{Considerações Iniciais}

As disciplinas de Estágio Curricular Supervisionado, do curso de Filosofia, $\mathrm{UFSM}^{2}$, buscam oferecer espaço para que os/as estudantes estabeleçam uma relação de implicação com a tarefa de ser professor $e$ professora no período específico da docência no ensino médio. $\mathrm{O}$ ato de se implicar com aquilo que se está a fazer demanda envolvimento, questionamento e desassossego. $\mathrm{O}$ Estágio é o momento de preparar aulas, ministrá-las, criar atividades didáticas, viver a

\footnotetext{
Professora Titular, Departamento de Metodologia do Ensino, Universidade Federal de Santa Maria, UFSM. elisetem2@gmail.com.

2 Estágio Curricular Supervisionado I e II, sob minha responsabilidade
}

vida escolar e depois relatar e avaliar o acontecido em um texto Relatório/Artigo. Mas é, também, muito mais que isso.

A implicação almejada considera que a condição de professor e professora em formação demanda algo mais que pensar $e$ planejar as aulas, que são tarefas fundamentais do processo de iniciação à docência. $\mathrm{O}$ objetivo que estagiários e estagiárias se impliquem com a docência se materializa ao serem conduzidos para que pensem sobre a perspectiva filosófica e metodológica que estão a assumir e apresentem argumentos que justifiquem tal escolha. Nesse movimento reflexivo o percurso formativo no curso de Filosofia assume centralidade; se lançam,

TOMAZETTI, Elisete M. Estágio em filosofia e práticas de experiência de si (docente). Revista SulAmericana de Filosofia e Educação. Número 34: nov. 2020 - abril 2021, p. 71-92. DOI: https://doi.org/10.26512/resafe.v2i34.35133 
pois, a recuperar os embates de perspectivas epistemológicas de disciplinas; a apontar as carências formativas; a analisar a formação recebida no atrito com a experiência docente $e^{3}$, no cotidiano da escola, da sala de aula, com todas as suas demandas e desafios.

Implicar-se, avaliar-se, narrar-se, pensar sobre si mesmo como professor e como professora são alguns dos termos que dizem de certos objetivos formativos; de certos processos de subjetivação, de práticas que colocam o sujeito em relação consigo mesmo, para que realize a experiência de si. Para que isso ocorra é necessário que alguns modos de organização sejam acionados, tais como: a roda de conversa que possibilita o dizer sobre o dia de estágio, sobre dificuldades, desafios e, também, sobre os encontros alegres e potentes que tiveram. A produção do projeto de estágio e do relatório, que convocam a escrita acerca de sua experiência como docente, ou seja, da experiência do estar se tornando professor e professora, tem um papel fundamental nesse momento. Os/as estudantes também são conduzidos a produzir seu Diário da Prática Docente ${ }^{4}$, du-

\footnotetext{
${ }^{3}$ Essa expressão é utilizada pelo professor Celso Favaretto em seu texto "Notas sobre ensino de filosofia", ao se referir à aprendizagem de filosofia na escola a partir do encontro de múltiplos signos com a experiência realizada pelos estudantes: "O ensino torna-se, assim, processo de constituição do espaço de encontro dos signos, possibilitando que o aprender se desenvolva pela exploração do atrito da linguagem na experiência" (FAVARETTO in: ARANTES et all., 1995, p. 84)

${ }^{4}$ O Diário da Prática Docente é uma ferramenta pedagógica utilizada em diferentes cursos de licenciatura; em projetos de formação continuada de professores e, também, como material para pesquisas sobre formação docente. As referências principais que me inspiraram a tomá-lo como uma ferramenta pedagógica para a formação de futuros/as professores e professoras de Filosofia são: El Diário del Profesor, Por-
}

rante o ECS II, quando estão em sala de aula como docentes. Essa prática sempre demandou um certo exercício de convencimento por parte da orientadora de Estágio; em anos mais recentes parece estar sendo melhor acolhida. Sua leitura e exposição ao grupo de colegas ocorre em determinados encontros, previamente agendados: os/as estagiários são convidados a ler trechos de seu diário, a comentá-lo e ouvir o que os/as colegas sobre ele comentam. O Diário é tomado, assim, como uma prática que realiza a mediação do sujeito consigo mesmo, para pensar sobre si no exercício da docência. $\mathrm{O}$ que nele escrevem reaparece em seus Relatórios/Artigos de Estágio e nas rodas de conversa, nos encontros semanais. Embora afirmemos que a constituição docente seja o resultado de um longo processo, pois se começa a ser professor quando se é aluno/a, lá na escola (CERLETTI, 2009), o momento do Estágio possibilita, de forma mais organizada e interessada, a construção da narrativa acerca da experiência docente de cada estudante, tendo como referência seus registros e sua memória da formação inicial.

É sobre os mecanismos de produção da experiência de si de estagiários e estagiá-

lán y Martin, 1997, e Diários de Aula, de Miguel Zabalza, 1994. O Diário é tomado como um componente fundamental para reconhecimento $e$ avaliação do que o/a professor/a realiza em seu movimento de ser docente. Como afirma Miguel Zabalza (1994, p. 10), "Escrever sobre o que estamos fazendo como profissional (em aula ou em outros contextos) é um procedimento excelente para nos conscientizarmos de nossos padrões de trabalho. É uma forma de 'distanciamento' reflexivo que nos permite ver em perspectiva nosso modo particular de atuar. É, além disso, uma forma de aprender". Essa escrita, escrita de si, do Diário não será nosso objeto de análise nesse texto, mas certamente é uma prática de produção do sujeito professor e professora que deve merecer nossa investigação em outro momento. 
rias, nas aulas de orientação do Estágio, que este texto trata. Experiência que se dá quando são levados, a partir de certos procedimentos ou tecnologias, a estabelecer relações consigo mesmos, cujo objetivo é "fixar sua identidade, mantê-la ou transformá-la em função de determinados fins, e, isso graças a relações de domínio de si sobre si ou de conhecimento de si por si" (FOUCAULT, 1997, p. 109). É, também sobre a tentativa de pensar sobre os modos de funcionamento das aulas de orientação do Estágio para poder nomeá-las e analisá-las, a partir de referências e de leituras que fazem parte de meu percurso de professora e pesquisadora. Esse texto traz para o âmbito da problematização questões acerca da relação entre os conceitos de experiência de si, práticas de si (tecnologias do eu) e o Estágio em Filosofia, e toma como referência primeira o texto de Jorge Larrosa, Tecnologias do Eu e Educação, publicado no Brasil como capítulo do livro $O$ sujeito da educação, organizado pelo professor Tomás Tadeu da Silva, em 1994

\section{Sobre Tecnologias do Eu}

O objetivo desta seção é explorar os conceitos de tecnologias do eu no âmbito da obra de Michel Foucault, que é demarcada, por seus estudiosos, em três grandes domínios: arqueologia, genealogia e ética. Cada um responde a uma pergunta e se estrutura em obras centrais. A arqueologia está centrada ao redor da pergunta pelo saber, entre os anos de 1961 e 1969, nas obras História da Loucura e Arqueologia do Saber, "passando por Nascimento da Clínica e As Palavras $e$ as Coisas" (VEIGA-NETO, 2007, p. 36). A segunda, a genealogia, tem como referência primeira a questão do poder, problematizada em obras como a Ordem do Discurso (1971) e Vigiar e Punir (1975) e História da Sexualidade, em seu primeiro volume. E, por fim, a terceira fase se estrutura em torno da questão do governo de si, da questão da subjetividade - das técnicas $e$ tecnologias do eu, da subjetivação. Entre as obras a destacar desta etapa estão: História da Sexualidade - O uso dos prazeres, volume 2 e História da Sexualidade - Cuidado de Si, volume 3 (MOREY, 2008). Esta apresentação da obra foucaultiana, em domínios, não raro pode indicar algo como "la sucesión de três procedimentos, cada uno de los cuales sustituiría al anterior. [...] Y ello es radicalmente erróneo. Los procedimentos metódicos se engloban en círculos cada vez más amplios, pero no se sustituyen en absoluto" (2008, p. 16).

Ao abordar a questão do poder na genealogia, o tema da moral já se faz presente. Morey retoma a entrevista de Foucault a Dreyfus e Rabinow denominada Por que estudar o poder: a questão do sujeito (2010), na qual afirma: "Assim, não é o poder, mas o sujeito, que constitui o tema geral de minha pesquisa". Essa referência tem o sentido de introduzir, aqui, as questões acerca da subjetividade, da produção do sujeito, e também afirmar a sua presença como questão ao longo da produção filosófica de Foucault. A emergência do sujeito como objeto de estudo de Foucault está indicada nos três eixos distintos de sua obra, segundo Miguel Morey (2008, p.25).

Ontología histórica de nosotros mismos en relación con la verdad que nos constituye como sujetos de co- 
nocimiento (Historia de la locura, Nacimiento de la clínica y Las palabras y las cosas).

Ontología histórica de nosotros mismos en las relaciones de poder que nos constituyen como sujetos que actúan sobre otros (Historia de la locura, Observación y Castigo).

Ontología histórica de nosotros mismos en la relación ética a través de la cual nos constituimos en sujetos de acción moral (Historia de la locura, Historia de la sexualidad).

O sujeito não mais é tomado como um universal, com características específicas, que seriam constituidoras de sua natureza. Mas, sim, é produzido historicamente, o que significa afirmar, então, a necessidade de analisar as condições de emergência dos modos de subjetivação. Ou, como nos diz Weinmann (2006, p. 16), "Suspeitar dos universais antropológicos implica perguntar pelos jogos de verdade que lhes oferecem sustentação". Para tanto, Foucault investigou as práticas discursivas e não discursivas constituidoras do sujeito e a sexualidade emergiu como uma questão central para o filósofo ${ }^{5}$. "Se trata de analizar la sexualidad como una experiencia históricamente única en la que el sujeto se objetiva para sí mismo y para los demás, a través de ciertos procedimientos gubernamentales precisos. (FLORENCE, apud MOREY, 2008, p. 33).

A questão do governo pode ser analisada na conexão entre as tecnologias políticas dos indivíduos e as tecnologias do eu;

\footnotetext{
5 "Finalmente, tentei estudar - meu trabalho atual - o modo pelo qual um ser humano torna-se ele próprio um sujeito. Por exemplo, escolhi o domínio da sexualidade - como os homens aprenderam a se reconhecer como sujeitos de 'sexualidade'." (FOUCAULT apud RABINOW; DREYFUS, 2010, p. 274).
}

entre as tecnologias de coerção $e$ as tecnologias de análise de si. As primeiras realizam a objetivação do sujeito para os outros; as tecnologias do eu produzem a objetivação do sujeito para si mesmo. Foucault, em seu texto Tecnologias do $E u$, diz que há quatro tipos principais de tecnologias: tecnologias de produção; tecnologias de sistemas de signos; tecnologias de poder, "que determinam la conducta de los individuos [...] y consisten en una objetivación del sujeto"; [e, por fim, as tecnologias do eu,] "que permiten a los individuos efectuar, por cuenta propia o con la ayuda de otros, cierto número de operaciones sobre su cuerpo y su alma, pensamientos, conducta o cualquier forma de ser, obteniendo así una transformación de sí mismos con el fin de alcanzar cierto estado de felicidad, pureza, sabiduría o inmortalidad." (FOUCAULT, 2008, p. 48).

Esses quatro tipos de tecnologia não funcionam isoladamente e de maneira sequencial, afirma Foucault, embora a cada uma esteja associado um tipo de dominação e envolva "ciertas formas de aprendizaje $y$ de modificación de los individuos, no solo en el sentido más evidente de adquisición de ciertas habilidades, sino también en el sentido de adquisición de ciertas actitudes" (FOUCAULT, 2008, p. 48-49). As tecnologias de produção se vinculam aos estudos nas ciências e as tecnologias de sistemas de signos no campo da linguística. No entanto, Foucault afirma que seus estudos e problematizações se voltaram bem mais para as tecnologias de poder e para as tecnologias do eu. Como exemplo oferece seu estudo sobre a loucura, cujo objetivo não foi permanecer circunscrito ao campo das ciências formais, mas "mostrar cómo, mediante este 
estraño discurso, era posible un cierto tipo de control de los individuos dentro y fuera de los asilos. Este contacto entre las tecnologías de la dominación de los demás y las referidas a uno mismo és lo que llamo gobernabilidad" (FOUCAULT, 2008, p. 49). A relação entre liberdade e dominação se torna, então, eixo importante do pensamento do filósofo, pois ao considerar as práticas de si e um sujeito que se volta sobre si mesmo, com o objetivo de transformar-se, invoca-se a questão da liberdade, ou melhor, de práticas de liberdade 6 . Por isso, "é possível afirmar que é em um processo agonístico que a subjetivação se produz. É porque há forças no sentido do seu assujeitamento que a subjetividade resiste e toma a si própria como objeto de elaboração (WEINMANN, 2006, p. 18).

A produção da subjetividade como experiência de si é o eixo que move a escrita deste texto, com o intuito de pensar sobre a produção de sujeitos professores e professoras em um momento específico da formação inicial - o Estágio. Trata-se de, com Foucault, elaborar a compreensão das técnicas de governo de si e considerar que o sujeito

\footnotetext{
${ }^{6} \mathrm{Na}$ obra Vocabulário de Foucault, de Edgardo Castro, o verbete Liberdade traz referências fundamentais, que auxiliam nossa compreensão acerca da diferença, para o filosófo, entre Liberdade e Práticas de Liberdade. "A liberdade foucaultiana não é da ordem da liberação, mas da constituição. [...] não é uma substância, é uma forma." Em sua relação com o poder, Foucault pensa em termos de práticas de liberdade, ou seja, as relações de poder se dão em um campo aberto de possibilidades. No caso da relação do sujeito consigo mesmo, no âmbito da ética, Foucault afirma "A liberdade é a condição ontológica da ética. Mas a ética é a forma reflexa que toma a liberdade". Não se trata de considerar a liberdade como "liberação", mas como práticas de liberdade, "isto é, da forma que podemos dar à subjetividade". (CASTRO, 2009, p. 246-47)
}

não aparece mais apenas como "resultado de uma operação de assujeitamento a um dispositivo; nessa nova perspectiva a subjetivação é concebida como um processo do qual um sujeito participa ativamente" (WEINMANN, 2006, p. 20). Temos,

assim, alguns elementos que tornam possível apresentar os argumentos centrais de nossa investigação, desde o campo da Educação. O sujeito se constitui como professor/a, também, a partir de tecnologias do eu; com a ajuda de outros sujeitos e de certos dispositivos pedagógicos que constroem e modificam a experiência que têm de si mesmos em seu processo formativo. Como já afirmado anteriormente, o texto Tecnologias do eu e Educação (LARROSA,1994) colocou em evidência, de forma bastante interessante, a riqueza da relação entre a problemática apresentada por Foucault e o campo das práticas educacionais, o campo pedagógico. Em especial, fui conduzida a pensar algo que ainda não pensava acerca de meu trabalho com a formação de professores/as de filosofia, em especial no momento do Estágio curricular. Ao analisar os modos de funcionamento das reuniões de Estágio, as tarefas a serem realizadas pelos/as estudantes e a minha forma constatei certas aproximações com as experiências narradas por Jorge Larrosa (1994). Passei, então, a realizar uma investigação sobre os materiais produzidos pelos/as estudantes do Estágio e a olhar de outro modo o funcionamento da disciplina e meu modo de conduzi-la, que se enquadra, pois, no critério definido por Larrosa para o estudo que realizou: "A única condição é que sejam práticas pedagógicas, nas quais o importante não é que se aprenda algo 'exterior', um corpo de conhecimentos, mas que se elabore ou ree- 
labore alguma forma de relação reflexiva do 'educando' consigo mesmo “ (1994, p. 2).

\section{Sobre Dispositivo Pedagógico}

Antes de adentrar as questões acerca da existência e das características do dispositivo pedagógico, considero importante apresentar alguns elementos que poderão ajudar na compreensão do conceito de dispositivo $e$ de sua emergência na filosofia foucaultiana. Não há aqui a intenção de fazer o registro detalhado acerca do conceito na obra do filósofo, mas oferecer elementos que nos ajudem a argumentar sobre sua utilização no campo da Educação, ou seja, a pensar o dispositivo no campo pedagógico - o dispositivo pedagógico.

Uma primeira observação acerca do conceito nos é dada pelo professor Sandro Chignola (2014, p.4):

Perguntamo-nos então, sobre a sua origem, onde Foucault buscou $\mathrm{O}$ termo "dispositivo". O argumento de Agamben é sugestivo. Foucault teria escolhido o termo como um "Ersatz" do conceito de "positividade" que ele havia utilizado anteriormente $e$ tomado de Jean Hyppolite (Introduction à la philosophie de l'histoire de Hegel, 1948).

Chignola (2014) se serve do texto de Agamben, $O$ que é um dispositivo? para explorar a emergência deste conceito na filosofia foucaultiana. Positividade tem sua origem nos estudos de Jean Hypolite sobre Hegel, nesse caso em especial, na obra $A$ Positividade da Religião Cristã (1795-96), na qual aparecem os termos religião positiva e religião natural. O termo religião positiva é explicado pela presença de "sentimentos que estão gravados na alma através de uma constrição e de comportamentos que são o resultado de uma relação de comando $e$ obediência, e que acontecem sem um interesse direto" (CHIGNOLA, 2014, p. 5). A positividade da religião diz respeito a sua condição histórica, de instituição que se materializa por

...uma relação de comando e obedi-
ência por meio dos rituais, liturgias
ou regras que se impõem sobre o as-
sunto a partir do exterior, mas, e este
é o segundo motivo, funciona a par-
tir do interior sobre o fiel, que inter-
naliza como sentimentos, atitudes e
formas de sua própria autopercep-
ção e autoconsciência, fórmulas e
preceitos em que a religião se "posi-
tiviza" como instituição. (2014, p. 5).

Positividade tem um sentido histórico; diz de regras que se impõem sobre os indivíduos e da relação entre eles, de seus processos de subjetivação e da presença das instituições. O termo dispositivo começa a ser utilizado por Foucault a partir dos anos 1970 e foi relacionado ao conceito de episteme (CHIGNOLA, 2014). É concebido como a região mediana "que se estende entre os padrões de percepção e linguísticos que moldam a experiência de mundo e o conjunto de saberes, procurando dar uma interpretação teórica ou científica do mesmo" (idem, p. 5). Episteme ou campo epistemológico é considerado, então, um espaço de ordem "que tornou possível o estabelecimento de um saber que a análise visa rastrear - para retomar por vez as suas palavras - o 'a priori histórico' [...]" (Idem, p. 6).

Esses elementos apresentados por Chignola indicam a complexidade do dispo- 
sitivo na obra de Foucault; não se trata de um termo unívoco que aparece claramente em um momento de suas pesquisas, sem conexão com outros já em operação. Dispositivo tem conexão com episteme, mas não é episteme, pois no fluxo de sua obra, ao adentrar o âmbito da genealogia para tratar das relações entre saber e poder, passa "acessar o espaço estriado pelo rumor dos saberes filosoficamente anônimos" (CHIGNOLA, 2014, p.7). O dispositivo é mais geral que a episteme, diz Foucault. "Ou melhor, que a episteme é um dispositivo especificamente discursivo, diferentemente do dispositivo, que é discursivo e não discursivo, seus elementos sendo muito mais heterogêneos" (FOUCAULT, 2008, p 246). Por fim, então, o conceito de dispositivo apresentado por Foucault na entrevista concedida a Alain Grosrichard.

\begin{abstract}
Através deste termo tento demarcar, em primeiro lugar, um conjunto decididamente heterogêneo que engloba discursos, instituições, organizações arquitetônicas, decisões regulamentares, leis, medidas administrativas, enunciados científicos, proposições filosóficas, morais, filantrópicas. Em suma, o dito e não dito são os elementos do dispositivo. O dispositivo é a rede que se pode estabelecer entre estes elementos. (FOUCAULT, 2008, p. 244).
\end{abstract}

Na sequência Foucault esclarece que "a natureza da relação que pode existir entre estes elementos heterogêneos" tem o caráter de jogo, "ou seja, mudanças de posição, modificações de funções, que também podem ser muito diferentes" (idem, p. 244). E o terceiro elemento diz respeito a uma "fun- ção estratégica dominante", por exemplo, no que refere ao "controle-dominação da loucura, da doença mental, da loucura", que se constituiu como dispositivo. Foucault esclarece: "Para dizer: eis um dispositivo, procuro quais foram os elementos que intervieram em uma racionalidade, em uma organização [...]" (2008, p. 246). Novamente a referência aos diversos e diferentes elementos que constituem uma rede que se estende sobre os indivíduos para produzi-los como sujeitos. Em outras palavras, dispositivo diz respeito "A um determinado agrupamento de práticas, que constituem um sujeito em uma trama de saberes e em um feixe de forças que lhe são imanentes" (WEINMANN, 2006, p. 17).

Logo no início de seu texto Jorge Larrosa adverte: "Trata-se, pois, de mostrar a lógica geral dos dispositivos pedagógicos que constroem e medeiam a relação do sujeito consigo mesmo, como se fosse uma gramática suscetível de múltiplas realizações" (1994, p.2). É o primeiro momento em que essa expressão ali aparece. Faço essa demarcação com o objetivo de explicitar o sentido operatório que o conceito assume em sua investigação sobre práticas pedagógicas, as quais produzem experiências formativas específicas. No entanto, não são todas $e$ quaisquer práticas pedagógicas que são tomadas, em seu texto, como dispositivo pedagógico, mas apenas aquelas "nas quais se estabelecem, se regulam e se modificam as relações do sujeito consigo mesmo e nas quais se constitui a experiência de si" (1994, p.9). Esta relação dos sujeitos consigo mesmos ocorre quando são levados, como escreve Foucault, "a prestar atenção a eles próprios, a se decifrar, a se reconhecer e se 
confessar como sujeitos do desejo, estabelecendo de si para consigo uma certa relação que lhes permite descobrir, no desejo a verdade de seu ser [...]" (FOUCAULT, 2012, p. 11-12). Também em busca por constituir práticas de si como cuidado ético; exercícios de "cuidado de si" e de governo de si, "não por força de um constrangimento, mas como uma prática de liberdade" (WEINMANN, 2006, p. 19) ${ }^{7}$. O dispositivo pedagógico é, pois, acionado para mediar a relação do sujeito consigo mesmo nesses diferentes eixos e é definido por Jorge Larrosa da seguinte maneira:

...qualquer lugar no qual se constitui ou se transforma a experiência de si. Qualquer lugar no qual se aprendem ou se modificam as relações que o sujeito estabelece consigo mesmo. Por exemplo, uma prática pedagógica de educação moral, uma assembleia em um colégio, uma sessão de um grupo de terapia, o que ocorre em um confessionário, em um grupo político, ou em uma comunidade religiosa, sempre que esteja orientado à constituição ou à transformação da maneira pela qual as pessoas se descrevem, se narram, se julgam ou se controlam a si mesmas" (1994, p.18).

Nesta definição, o lugar e o tipo de prática formativa assumem centralidade $e$ cumprem "determinadas regras e determinadas formas de realização" (idem, p. 19). O

\footnotetext{
7 "Voltando à Antiguidade grega e ao cristianismo, Foucault passa a considerar as práticas de si que produzem um sujeito ético. Não mais um sujeito que se dá apenas como 'resultado de uma operação de assujeitamento a um dispositivo, [mas] nessa nova perspectiva a subjetivação é concebida como um processo do qual um sujeito participa ativamente" (WEIMANN,2006, p. 20).
}

conceito dispositivo tem um caráter amplo, pois articula vários elementos heterogêneos, como "discursos, instituições, organizações arquitetônicas, decisões regulamentares, leis, medidas administrativas, enunciados científicos, proposições filosóficas, morais, filantrópicas" (FOUCAULT, 2008, p. 244). Para fazer o estudo dos dispositivos pedagógicos, Jorge Larrosa apresenta um "modelo teórico" composto por cinco dimensões: dimensão ótica; dimensão discursiva, dimensão jurídica; narrativa e por fim, uma dimensão prática ${ }^{8}$. Estas dimensões serão acionadas na análise das práticas do Estágio Supervisionado em Filosofia, a partir das exigências das narrativas, que compõem a materialidade da qual me ocupo nesta escrita.

\section{Narrativas de Formação em Filosofia nos Escritos do Estágio}

\author{
[...] o que se pre- \\ tende formar e transfor- \\ mar não é apenas o que \\ o professor faz ou o que \\ sabe, mas, fundamen- \\ talmente, sua própria \\ maneira de ser em rela-
}

\footnotetext{
${ }^{8}$ Dimensão ótica, "aquela segundo a qual se determina e se constitui o que é visível dentro do sujeito para si mesmo. [...]. Em continuação, uma dimensão discursiva, na qual se estabelece e se constitui aquilo que o sujeito pode e deve dizer acerca de si mesmo. Em terceiro lugar, uma dimensão jurídica, basicamente moral, em que se dão as formas nas quais o sujeito deve julgar a si mesmo segundo uma trama de normas e valores. Quarto, e em uma dimensão que inclui, relacionando-os, componentes discursivos $e$ jurídicos, [...] é a narrativa; esta é a dimensão na qual a experiência de si está constituída de uma forma temporal e aquela que determina, portanto, aquilo que conta como um personagem cuja continuidade $e$ descontinuidade no tempo é implícita a uma trama. Por último, uma dimensão prática que estabelece o que o sujeito pode e deve fazer consigo mesmo" (LARROSA, 1994, p. 19).
} 
ção a seu trabalho. (LARROSA, 1994, p.

Embora haja programa e ementa das duas disciplina de Estágio ${ }^{9}$, não se trata, exclusivamente, de abordar temas ou conteúdos previamente indicados. Certamente que há seminários, leituras e discussões, mas estes são definidos no percurso, conforme as necessidades e solicitações dos/das estudantes.

Nos encontros da disciplina Estágio Curricular Supervisionado I, ECS I, a produção do projeto de estágio é central. Demanda retomada, avaliação e rearticulação dos saberes, das práticas e dos sentidos do ensino de filosofia; vão para a escola, fazem a cartografia, e projetam sua docência em Filosofia para o ECS II, que ocorre no semestre subsequente. O Estágio é o momento de tentar o exercício autoral, de rememorar, de pensar sobre, de colocar em dúvida, de haver-se consigo mesmo, com sua formação, com seus desejos e suas angústias em relação à docência.

A escrita do projeto, do relatório ou artigo final do Estágio ${ }^{10}$ oferece a possibili-

\footnotetext{
${ }^{9}$ O Estágio é constituído de duas disciplinas, Estágio I e Estágio II; comporta uma parte teórica e outra prática. A parte teórica é de $60 \mathrm{~h}$, presencial, nas quintasfeiras, das $14 \mathrm{~h}$ às $18 \mathrm{hs}$. Neste dia e horário é construído um espaço de conversas e de trocas com o grupo de estudantes. Faz-se seminários sobre temas considerados relevantes para o Estágio. A parte prática diz respeito à produção dos materiais solicitados, preparação das aulas, presença na escola para diversas atividades, regência de aulas.

${ }^{10}$ As produções escritas solicitadas para os/as estagiários/as são: projeto (ECSI) e relatório de estágio (ECSII), para os quais é oferecido um roteiro com questões a serem desenvolvidas e o Diária da Prática Docente. No entanto, podem optar também, no ECS II, pela produção de um artigo sobre a experiência do
}

dade de o estagiário e a estagiária examinar e manifestar suas certezas e incertezas; suas teorias e verdades sobre filosofia e ensino de filosofia; sobre escola, sobre didática e sobre estudantes, que também são jovens. É nesse movimento de pensar sobre educação e sobre ensino da filosofia que podem construir "[...] uma determinada auto-consciência pessoal e profissional que sirva de princípio para a prática, de critério para a crítica e a transformação da prática, e de base para auto-identificação do professor" (LARROSA, 1994, p. 13).

[...] o projeto exige uma exteriorização, organização e encadeamento de ideias. O projeto deve ser coerente como um todo, exigindo não simples definições ou exposições arbitrárias, mas que cada ideia possua uma certa relação com a outra. $\mathrm{O}$ ato de expressar tais ideias resulta em um aprendizado por si só, pois é no exteriorizar que vemos lacunas, erros $e$ contradiçôes. Portanto, além da importância da dedicação ao pensamento sobre os temas, há uma importância no próprio processo de organização por escrito dos resultados destas reflexões. Escrever foi também refletir, e me proporcionou ver obstáculos a serem superados e outras perspectivas sobre o que antes em pensamento parecia muito correto. (Renato, Projeto de Estágio,2019).

\footnotetext{
Estágio. Essas produções são entregues em forma de arquivo digital e também de forma impressa para que fiquem à disposição da comunidade do curso de Filosofia no Laboratório de Ensino e Aprendizagem Filosófica, LEAF. Os Diários podem ser recolhidos pelos estagiários/as ao fim do semestre letivo; no entanto, se desejarem, podem deixá-lo disponível no Laboratório.
} 
A escrita solicitada no período do Estágio permite o aparecimento de "lacunas, erros e contradições", que são resultantes do processo formativo, institucional e curricular, mas também daquilo que esteve em suas margens. Pensar sobre o ensino da filosofia a partir da escola, da turma, dos estudantes $e$ do/a professor/a tutor/a, entre outros elementos, realiza o atrito entre ideias e experiência e, assim, conduz à elaborar outros movimentos de docência. Desta forma, escrever sobre as experiências do Estágio em Filosofia tem um caráter de desafio, pois se insiste, como parte do dispositivo pedagógico, na mediação do sujeito consigo mesmo. Há, sim, uma preocupação com a retomada e o estudo de temas específicos de filosofia, que serão desenvolvidos nas futuras aulas; há o planejamento das aulas, que se insere em uma vasta dimensão de complexidade. Mas, há também, e é isso que gostaria de salientar aqui, de modo a defender minha argumentação neste texto, um exercício de voltar-se para si mesmo, de perguntar e analisar como chegaram, estagiários/as, a pensar o que pensam, a escrever o que escrevem, nos materiais solicitados durante o Estágio. Trata-se, pois, de um tipo de escrita que alguns/mas definem como ensaística, como vemos no excerto abaixo.

Convém saber, antes de tudo, que a escolha pelo modo ensaístico de escrever não é a toa - e nem se deve unicamente ao meu apreço por ele. Tanto quem lê, quanto quem escreve ensaios precisa saber que este modo de escrita (tão difundido e mal compreendido nos dias de hoje) permite uma escrita mais livre e imaginativa, e visa através da própria escrita dar a conhecer quem escreve e aquilo que fez, ou seja, constitui-se como um exercício para a obtenção de autoconhecimento. Mas isso não se reduz a uma simples narrativa, uma vez que a escrita de ensaios tem por base a reflexão e avaliação das experiências através do uso da faculdade do juízo. Reflexão e avaliação também são elementos que estavam presentes durante a prática de ensino no Estágio. Neste sentido, as reflexões que apresentarei aqui podem ser justamente aquelas que foram realizadas no transcorrer do Estágio na escola". (Leandro, Relatório de Estágio, 2014).

O modo ensaístico de escrever não é uma prática comum durante o curso, mas no Estágio tem presença de destaque. Como já afirmado anteriormente, as produções escritas dos/as estagiários/as não são exigidas como forma de cumprir apenas o seu sentido formal e institucional, também importante e necessário. Como parte do dispositivo pedagógico das disciplinas ECS I e ECS II, a escrita tem o sentido de possibilitar que se reconheçam como sujeitos professores e professoras; que reconheçam seu jeito/estilo de ensinar. Pode-se considerar que essa atividade é da ordem da visibilidade, do voltar "o olho da mente para dentro" (LARROSA, 1994, p. 20), pois quando escreve o/a estagiário/a, como sujeito, ele/a "se torna visível a si mesmo em sua interioridade. [E essa visibilidade é resultante] dos dispositivos que o fazem ver e orientam seu olhar, os quais são históricos e contingentes" (idem, p.22). Dizem do dispositivo pedagógico, amplo, que é o curso de formação de professores, nesse caso, o curso de licenciatura em Filosofia, mas também de todos os outros elementos que o constituem, como materiais didáticos, produção acadêmica sobre o ensi- 
no da Filosofia e diferentes materiais normativos, legais, entre outros. A produção de sujeitos, que veem a si mesmos, demanda, pois, o dispositivo pedagógico que "inclui um mecanismo ótico que a pessoa tem que fazer funcionar consigo mesma, aprendendo suas regras de uso legítimo, isto é, as formas corretas de ver-se" (LARROSA, 1994, p. 23). Entretanto, estas "formas corretas de ver-se" podem ser deslocadas e esta relação consigo mesmo/a vir a assumir um caráter de subjetivação, na qual se encontra a busca por práticas de liberdade.

A memória de práticas formativas do curso de Filosofia se faz presente. O professor/a que está se constituindo aparece, então, para si mesmo/a, como resultado desta formação. Este aparecimento lhe oferece a oportunidade, também, de resistir a certas verdades, de almejar outras práticas e também de ver-se de outro modo. A matriz curricular do curso é, então, vista, revista e criticada pelos/as futuros/as professores e professoras.

A formação didático-pedagógica é um dos elementos que ganha visibilidade quando estagiários/as se põem a analisar sua trajetória formativa. Durante grande parte de minha atuação como responsável pelas disciplinas de ECS I e ECS II, a referência à pequena presença dos estudos pedagógicos no curso de Filosofia, ou da denominada formação didático-pedagógica, é frequente. Reaparece quando são levados a falar sobre sua trajetória no Curso de Filosofia, como nos excertos abaixo.

Nossa formação didático-pedagógica é restrita, com disciplinas, como psicologia da educação, muito distantes da realidade escolar. A partir do $4^{\circ}$ semestre do curso temos o primeiro contato propriamente dito com questões acerca do ensino de filosofia. (Paulo, Relatório de Estágio, 2018).

Através somente das poucas disciplinas voltadas para a licenciatura especificamente para a licenciatura de filosofia não me sinto preparado para vivenciar este espaço composto de relaçôes das mais variadas, pois não percebo relação alguma do que estudo como uma possível aula de filosofia no ensino médio. Felizmente sou salvo por duas disciplinas, a saber, Pesquisa para o Ensino de Filosofia no terceiro semestre e Didática em Filosofia no quarto e agora com o Estágio Curricular Supervisionado I, entretanto mesmo isso não é suficiente para preparar integralmente um docente capaz de lidar com os jovens, por que essa formação se dá no decorrer da carreira. Contudo, nas demais disciplinas há raras menções à licenciatura, há raras disciplinas que aprofundem questões relativas à licenciatura, desta forma prejudicando a minha formação. (Marcos, Relatório de Estágio, 2012).

É necessário que os professores em formação tenham contato direto com a escola e que, além disso, reconheçam as condiçôes da filosofia no ensino médio e reconheçam a situação nada fácil das escolas públicas brasileiras. De modo que assim possam indicar, a partir do reconhecimento das dificuldades, possibilidades reais para o fortalecimento do ensino de filosofia e da educação como um todo. (Luíza, Projeto de Estágio, 2016).

O que se percebe, pois, são ditos sobre um curso com caráter dualista; que se constitui pela nítida separação entre uma formação em Filosofia, com seu caráter es- 
pecífico, e uma formação, que diz respeito ao ensino da Filosofia, a qual se situa na referida dimensão didático-pedagógica. Acionar essa expressão é, pois, acionar um conjunto de elementos que nela se insere como: a escola e sua complexidade; os materiais a serem utilizados em sala de aula; a legislação $e$ as normativas curriculares; os estudantes, suas diferenças e suas relações com a escola, entre outros. Então, ao pensar a docência em Filosofia parece inevitável olhar para o currículo do curso, suas disciplinas, suas abordagens e suas práticas empreendidas para formar professores e professoras de filosofia com certa identidade pessoal e profissional. As narrativas acerca das vivências no curso "implica imaginação e composição, implica um certo sentido do que somos, implica habilidade narrativa" (LARROSA, 1994, p. 28). Implica, por outro lado, também, a tentativa de encontrar e demonstrar as fissuras dessa formação, de maneira que possam produzir abertura para pensar e fazer a docência de outros modos. O PIBID ${ }^{11}$, por exemplo, aparece como um possível, que produziu outros sentidos e outros modos de pensar e viver a docência em Filosofia du-

11 O Programa Institucional de Bolsas de Iniciação à Docência, PIBID, criado pela CAPES em 2007, tem desde então, entre seus valiosos objetivos o de modificar a formação de professores da Educação Básica, realizando uma maior articulação entre universidade e escola, através de projetos de inserção e de colaboração. Aproximou estudantes de licenciatura das escolas, os fez pensar sobre o ensino em toda a sua complexidade. Mas, em meu modo de analisar, foi, ao menos em seus anos iniciais, uma linha de fuga, um espaço de resistência no âmbito do curso de Filosofia. Tornou visível para a comunidade filosófica, de minha universidade, que era momento de ter um olhar respeitoso para com as questões do ensino da filosofia. Para os estudantes tornou-se um espaço, também, de reconhecimento dos desafios e alegrias da docência. rante o curso. No entanto, há outros pontos a serem destacados: as discussões, os estudos e os seminários sobre os temas: Mulheres e Filosofia, Feminismo, Questóes de Gênero, Filosofia Africana, que mesmo ausentes, em grande medida, do currículo e das aulas, compõem, de modo marginal ${ }^{12}$, a vida acadêmica de muitos/as estudantes de Filosofia. No momento do Estágio se fizeram presentes; foram acionados nos projetos, nas aulas, nos materiais didáticos, por exemplo. Jéssica Erd Ribas, ao realizar uma genealogia da formação filosófica na UFSM a partir de projetos e relatórios de Estágio em um período de 10 anos, identificou a presença de temas sempre secundarizados e/ou excluídos da formação canônica.

Em nossa análise identificamos que os/as estudantes criam seus espaços de fuga e encontram meios de tratar sobre os assuntos que uma vez marginalizados pelo cânone ocidental, branco e patriarcal do discurso filosófico, não aparecem na grade curricular do curso. São espaços que se configuram como "sopros de vida" -

\footnotetext{
12 A dissertação de Jéssica Erd Ribas, defendida no Programa de Pós-Graduação em Educação da UFSM, intitulada Estágio Curricular Supervisionado e suas dobras: uma genealogia da formação filosófica na UFSM, 2019, faz uma problematização acerca do que denomina de um "filosofar no Olimpo". Pergunta se se estaria condenado a este tipo de formação; se não seria possível pensar em linhas de fuga. E ela responde: "Esses questionamentos há algum tempo povoam meus pensamentos e estão presentes também nos pensamentos e atos de fala de vários/as colegas do curso de Licenciatura em Filosofia da UFSM. Essas linhas de fuga ganham corpo e se materializam nas paredes do Diretório Acadêmico da Filosofia (DAFIL), nas conversas de corredores, nas temáticas dos nossos cafés no "Filosofia de Quinta", nos eventos que organizamos: as Semanas Acadêmicas da Filosofia, os Seminários PIBID Filosofia e Filosofia na Escola, e agora também em minha dissertação de mestrado." (RIBAS, 2019, p.101).
}

Número 34: nov. 2020 - abril 2021 
ânimas - que ruminam velhos conceitos dando-lhes uma atualidade $e$ tornando-os possíveis outra vez, desde um tempo outro, de um lugar outro, de problemas sempre outros. A respeito disso, encontramos em Deleuze, a compreensão de um "entre-lugar" [...]. (RIBAS, 2019, p. 109)

A filosofia é tradicionalmente masculina, e penso que levar as filósofas ao ensino médio já é uma forma de resistir, estudando a tradição filosófi$\mathrm{ca}$, pois nela existem muitos problemas importantes, mas também estudando a filosofia renegada pela tradição. (Regina, Projeto de Estágio, 2018).

Com o avanço de meu percurso formativo, e minhas interrogações constantemente crescentes a respeito do ensino de filosofia, meu objeto do projeto de estágio não poderia ser outro se não uma problemática do modo como está sendo reproduzida nas escolas básicas e nos cursos de graduação uma tradição excludente da história da filosofia ocidental, e as perceptiveis representações que esse silenciamento demonstra ao longo do aprendizado em filosofia. (Helena, Projeto de Estágio, 2019).

É indispensável reconhecer a experiência que o PIBID - trouxe a mim enquanto docente, mostrou-me o quanto é importante sabermos nos conduzir entre a 'ponte' das Universidades $e$ as escolas públicas. Infelizmente, muitos de nós traçamos o nosso caminho acadêmico para longe de onde realmente somos necessários, a saber, a escola pública. Obviamente, reconheço que são vários os motivos que levam a maioria dos alunos de licenciatura a escolherem esse caminho desde a baixa valorização da profissão à relação política conturbada dos governos federais $e$ estudais. (Carla, Projeto de Estágio, 2016).

Narrativas sobre Tornar-se Professor e Professora de Filosofia

A consciência de si própria não é algo que a pessoa progressivamente descobre e aprende a descrever melhor. É, antes, algo que se vai fabricando e inventando, algo que se vai construindo e reconstruindo em operações de narração e com a narração. (LAR-

ROSA, 1994, p. 30)

As narrativas acerca do estar sendo professor e professora, que interroga pelo sentido desse ofício e pelo jeito como se atua em sala de aula, têm centralidade nos escritos dos/as estagiários/as. É preciso, no entanto, considerar que dizer de suas histórias de professor e professora, como estagiários/as, não tem o caráter de uma iluminação ou de um reconhecimento acerca de quem se é verdadeiramente. As narrativas são discursos produzidos a partir de diferentes dispositivos, entre eles, aqui, o dispositivo pedagógico e seus elementos heterogêneos. Por isso, cabe aquele/a que analisa tais narrativas ter a capacidade de perguntar, como nos diz Jorge Larrosa (1994, p. 31), "pela gestão social e política das narrativas pessoais, pelos poderes que gravitam sobre elas, pelos lugares nos quais o sujeito é induzido a interpretarse a si mesmo, a reconhecer-se a si mesmo", ou seja, ser capaz de evidenciar os mecanismos de produção da identidade. 
As tarefas de mediação do sujeito consigo mesmo, propostas no Estágio, ou dizendo de outro modo - os "mecanismos de produção da experiência de si" (idem, p. 9), abrem uma brecha no tempo corrido da vida acadêmica e tornam possível escrever sobre a experiência de estar se tornando professor/a, que é vivida com angústia, medo e desafio. Os/as estagiários/as são levados a parar e pensar sobre si e sobre o que fazem, sobre porque fazem da forma como fazem ou por que pensam acerca da docência em Filosofia, do ensinar Filosofia. Trata-se, pois, de uma experiência formadora; ao escrever para cumprir uma atividade do Estágio, eles/as escrevem para si mesmos/as, mas também para outros que serão seus leitores $^{13}$.

Estar se formando professor e professora de filosofia, em especial no ano de 2019, em cenário desalentador para Educação e para as Ciências Humanas ${ }^{14}$, fez emer-

13 Os projetos e relatórios/artigos ficam disponíveis para leitura no LEAF. Os leitores destes materiais são todos aqueles interessados nas questões de ensino da filosofia e a própria orientadora de Estágio que conduz a sua produção.

${ }^{14}$ Desde o ano 2016 um cenário desalentador para a Educação e para as Ciências Humanas vem sendo produzido. Nesse ano foi emitida a MP 746/2016, que resultou na Lei $n^{\circ} 13.415$, de 2017; ela alterou a LDB 9394/1996. O Artigo 35-A, parágrafo $2^{\circ}$, se refere a mudança de estatuto da disciplina Filosofia para a denominação, ainda indecifrável, de "estudos e práticas": "A Base Nacional Comum Curricular referente ao ensino médio incluirá obrigatoriamente estudos e práticas de educação física, arte, sociologia e filosofia". A reforma do Ensino Médio, que está ainda sendo implementada, tem um caráter de retrocesso; haverá o empobrecimento da formação dos estudantes, pois não terão acesso, de forma igualitária, durante os três anos, a todas as disciplinas do currículo escolar. Apenas Português, Matemática e Inglês permanecem como obrigatórias nos três anos. Ao transformar as disciplinas de Filosofia, Arte, Sociologia e Educação Física em "estudos e práticas" as atuais políticas curri- gir sentimentos contraditórios: sim, quero ser professor, gosto disso; mas como sobreviver? A situação dos professores/as com salários parcelados no Rio Grande do Sul já há bastante tempo; de escolas sucateadas; de estudantes desanimados e de normativas curriculares, como a Reforma do Novo Ensino Médio, levou um estagiário produzir a narrativa que segue abaixo.

Mesmo que continuemos a tarefa de
diagnosticar a realidade escolar e a
imaginar atitudes e propostas para o
ensino de filosofia, o que se intenta
nesse mais novo roteiro para o Está-
gio Curricular Supervisionado é co-
locar os pés no chão, e na tangente
de um círculo de raios utópicos e dis-
tópicos, imaginar uma linha, como
podemos dizer, supertópica? Isto é, o
que se pode fazer com o que dispo-
mos aqui e agora, a partir do único
lugar que nos foi dado? Ainda é pos-
sível viver o presente ou já estamos
condenados a antecipar um desas-
tre? Este projeto depende de um cer-
to imperativo categórico: tem de ha-
ver algo no presente que nos faça
perceber, que nos faça sentir e que
nos faça mover, algo pelo qual ainda
valha a pena ser um professor e en-
sinar filosofia. (Luiz, Projeto de Es-
tágio, 2019).

Há, nesse movimento narrativo, um exercício de auto-crítica, de avaliação, de julgamento sobre o modo de ser professor/a, a partir de referências. Estas podem ser impostas como uma lei, uma norma ou um estilo. Segundo Larrosa (p.34-35), "a norma, diferentemente da lei pretende ser um con-

culares apontam para a desvalorização das Ciências Sociais e Humanas, que vem sendo reforçada pelas práticas de ataque de nossos atuais governantes à Ciência, de forma geral, e à formação universitária. 
ceito descritivo. [...] O normal se converte em um critério que julga e que valoriza positivamente. [...] critério complexo de discernimento: sobre o louco, o enfermo, o criminoso, o pervertido, a criança escolarizada". Por sua vez, o estilo não está ligado ao obrigatório; são artes da existência, "são práticas do eu que não foram capturadas, nem por um código explícito de leis sobre o permitido e o proibido, nem por um conjunto de normas sociais" (idem, p. 35). A escrita, como uma prática que faz a mediação do sujeito consigo mesmo, vai modulando o olhar, a narrativa e o julgamento acerca de sua identidade docente. No excerto que segue, o estagiário descreve sua busca por encontrar seu estilo como docente, ou seja, por elaborar a si mesmo de maneira ética e estética.

\section{"Como tornar-me o/a docente que quero?"}

Aprendemos a nos comportar em sala de aula, seja no papel de mestre ou no de ouvinte, desde nosso primeiro contato com a escola, pois a formação docente inicia-se desde os anos primários (CERLETTI, 2009). Em dado momento, como aprendiz, questiono-me sobre a eficácia do ensino escolar, e quantos outros docentes não foram pegos por tal dúvida? Meus potenciais e dos meus colegas, nosso saber, é aproveitado e ampliado aqui em sala de aula? Posso, com isso que recebo aqui, orientarme no caos do mundo? Melhorar-me - ou reconhecer-me, enquanto sujeito? Em dado momento decido ser docente, para tornar reais os potenciais de aprendizado do momento escolar; e deixando a escola eu adentro em um curso de licenciatura, eis o início de uma formação docente profissional - tarefa sinuosa, já que tantos exemplos meus de do- cência me fizeram almejar uma mudança. Como tornar-me o docente que quero? Socializar saberes valiosos com as turmas, ampliar seus potenciais existentes, fornecer uma experiência que contribua na sua relação sujeito-mundo. Como fazer isto? $\mathrm{Eu}$, que nunca lecionei. Eu, que sempre fui aprendiz. Durante a formação nos é dado teoria e prática. Aprendo teorias, mas como posso ensiná-las e transformar meu aprendizado em matéria valiosa e significativa a ser discutida, torná-lo um impulso de mudança na vida das e dos sujeitos que frequentam o espaço escolar? Vejo que minhas dúvidas não se respondem no pensamento particular, mas sim na própria experiência de dar aula. (Renato, Projeto de Estágio, 2019).

Embora reconheça, em seu percurso formativo, maneiras de ser docente que assumem caráter universal, pois sustentadas pela lei e pela norma, quando o estagiário faz a pergunta - como tornar-me o docente que quero? - indica uma tentativa de sujeição pelo estilo, ou seja, uma tentativa de se constituir pela via reflexiva, ética e estética de si mesmo. Atua, assim, de um modo que não é apenas resultante de práticas oriundas da lei e da norma, mas situado no âmbito da "estética da existência"15; diz de sua busca

$15 \mathrm{O}$ conceito de estética da existência foi elaborado por Foucault a partir de seus estudos sobre a Antiguidade Grega e está vinculado às questões éticas. "Por estética da existência há que se entender uma maneira de viver em que o valor moral não provém da conformidade com um código de comportamentos, nem com um trabalho de purificação, mas de certos princípios formais gerais no uso dos prazeres, na distribuição que faz deles, nos limites que se observa, na hierarquia que se respeita. [...] A problemática da liberdade, entendida como não escravidão, encontrase no coração dessa ética: não ser escravo dos outros, não ser escravo de si mesmo ou, em termos positivos, 
por atuar no espaço escolar, como docente de Filosofia, ensaiando práticas de liberdade.

\section{"O estágio nos faz lembrar de nós mesmas"}

"[...] é impossível não colocar aqui o quanto o estágio nos faz lembrar nós mesmas, se tem uma coisa que raramente avistamos em outros projetos são os nossos sentimentos ali envolvidos; o que normalmente ocorre é apenas um diagnóstico, uma perspectiva nossa sob aquilo que estamos observando, decisóes de como vamos fazer as nossas aulas, as nossas unidades didáticas, porém, nunca é falado sobre o que nos afeta quando observamos; tão pouco colocamos esse afeto em palavras. Então tenho de abrir esse parêntese e dizer que de repente ao me deparar com essa estrutura (e também com essa geração de alunos), vi uma Rosana com quinze anos falando com os amigos e com o primeiro amor da adolescência sobre questões raciais, questões de gênero $e$ questões do movimento LGBT lé claro, que de maneira muito superficial), e tendo muito pouco espaço para falar sobre. A minha escola não estava localizada no centro da cidade, ainda assim tinha uma arquitetura razoável, mas essa arquitetura nem sempre expressava sobre o que a gente falava na sala de aula e nos corredores. É notório e simplesmente emocionante acompanhar tal progresso, a Rosana de quinze anos estaria certamente mais representada estruturalmente se tivesse vivido o que os meus olhos como estagiária me permitiram ver hoje no presente. Mas não termina aqui, é necessário que todas as escolas tenham o mesmo, e, além disso, que se tenha filo-

governo dos outros e governo de si mesmo. " (CASTRO, 2009, p. 151). sofias (que atualmente) se encontram na periferia do mundo filosófico, mas que espero não de forma tão utópica estarem lado a lado com os outros tipos de filosofia e assim saiam do esquecimento histórico $e$ do ofuscamento que a história etnocêntrica e patriarcal o fez". (Rosana, Projeto de Estágio, 2019).

Na escrita de seu projeto, a estagiária fala de afetos e de como sua presença na escola acionou suas lembranças de quando era aluna de ensino médio. O contato com as estudantes e ouvir suas questões lhe reporta ao seu tempo de aluna, com quinze anos, tendo a mesma vontade de pensar e conversar sobre aqueles temas, certamente muito mais estranhos ao universo escolar. A professora que agora está se constituindo em meio a memória de sua vida de estudante retoma questões que lhe eram caras na época e que reencontra em suas jovens alunas. Faz um alerta a si mesma e a seus futuros leitores e leitoras: que as filosofias que "atualmente se encontram na periferia do mundo filosófico" possam adentrar a sala de aula das escolas e que não sejam abandonadas ao esquecimento. Reafirma sua implicação com as questões de gênero, feminismo, mulheres e filosofia durante o curso de filosofia e toma o Estágio como uma brecha que se abre para trazê-las à sala de aula da escola de ensino médio. Para além dos conteúdos e abordagens tradicionais - "história etnocêntrica e patriarcal" - que lhe foi ensinada $e$ será transmitida, insere, como um ato de resistência, como linha de fuga, as filosofias que ficaram em seu percurso formativo na "periferia do mundo filosófico".

\section{"Me descobri professora"}

Número 34: nov. 2020 - abril 2021 
A iniciação à docência foi algo transformador, descobri um ser em mim que não sabia que existia, me descobri como professora. As experiências adquiridas foram profundas. Estar realmente em sala de aula $e$ acompanhar uma turma, o crescimento dela, o amadurecimento dos alunos $e$ as aprendizagens adquiridas só constatou que o que quero para o futuro realmente é a docência. Agora considero estar preparada para adentrar no mundo do trabalho, sei que haverá dificuldades ao longo dessa jornada, mas percebo que sou apta para enfrentá-las. (Maria, Relatório de Estágio, 2018).

Ter podido pisar no chão da escola, conviver com os e as estudantes, desafiar-me sempre mais para que uma boa e interessante aula fosse ministrada, assim como perceber as mazelas e as dificuldades do ensino básico foi um desafio sem tamanho que trouxe muita aprendizagem $e$ gratidão, mas também inúmeras preocupações. Eu definitivamente não tinha noção de que o estágio pudesse mudar de maneira tão drástica a minha visão do que é ensinar, ministrar uma aula e do que é estar presente enquanto professora em uma escola. Todo o afeto recebido, seja pelos/as estudantes, seja pelos/as profissionais, foi indispensável para que eu tivesse forças para planejar e ministrar as aulas, em suma, de continuar nesta profissão a qual eu escolhi. (Sandra, Relatório de Estágio, 2017).

Nos excertos acima, as estagiárias dizem da "descoberta da docência" e nesse dito nos remetem a pensar que esta, a docência, estaria adormecida durante a formação inicial e o estágio teria sido o momento derradeiro no qual puderam finalmente descobrirem-se professoras. Há que se atentar, no entanto, que o sujeito professor/a não se descobre, de um momento para outro; o movimento é bem mais complexo. Como já referido anteriormente, estamos tomando o sujeito professor/a como produzido por determinadas condições que tramam uma história, marcada por relações de força e por determinados saberes. No caso específico aqui colocado em questão, o dispositivo pedagógico do Estágio, pela mediação da escrita, captura os/as estagiários/as para escreverem sobre si e a escrita atua como uma "máquina[s] de fazer ver e de fazer falar" (DELEUZE, 2006, p. 89). Ao afirmar a descoberta da docência as estagiárias dizem do reconhecimento do que estão fazendo; do que se estão sendo naquele momento específico. Nesse dizer afirmam um processo formativo que, de alguma forma, tornava invisível a condição da docência. $\mathrm{O}$ ato de "descobrir-se" as conduziu à construção de diferentes sentidos para a docência em Filosofia, que poderia ser de negação e recusa da docência, porém, assumiram o sentido da aceitação e do compromisso do ensinar Filosofia.

\section{"Espero, portanto, conhecer-me como do- cente"}

Aprender a lecionar é um ato empírico, ter este contato tátil é essencial para auto-descoberta docente. Espero, portanto, conhecer-me como docente, contrastar meu saber abstrato com a vivacidade discursiva e prática da sala de aula, aproveitando da conexão atual da universidade $e$ as vantagens que isto proporciona. Aprender a lecionar não é aprender 
apenas determinados saberes, mas sim determinados movimentos. Descubro aqui, no estágio curricular supervisionado, a minha maneira de movimento e como ele pode sintonizar com o dos e das educandas, para que assim possa surgir uma contribuição significativa no contexto educacional. Eis o início de uma incorporação de um agir pedagógico, um processo de exploração, tentativa $e$ erro, vislumbre e espanto, frustração e satisfação. (Renato, Projeto de Estágio, 2019)

Há ainda um encanto a mais na labuta do educador. Refiro-me a ideia de formação. Está-se diante de seres humanos ainda imaturos, dispostos a imaginar um futuro ainda repleto de possibilidades, afinal, por que resignar-se ao mundo sob o aspecto que se encontra? $O$ educador pode entregar-se a manufatura de algo novo, descobrindo que tal novidade também é sua, havendo espaço para reinventar-se justamente porque os educandos renovam-se constantemente. Obviamente sei que aqui está a pensar a parte de mim que ainda sonha, então porque aceitar os devaneios? Porque esta é a parte de mim que ainda vive. (Luiz, Projeto de Estágio, 2019).

A radicalidade do interrogar deve ser parte constante da prática de ensino sobre ela mesma. Quando o professor questiona a si mesmo sobre os porquês de sua prática, de se ensinar filosofia, de se ensinar filosofia para um certo grupo específico de alunos, de como fazer, ele se constitui como o "propulsor no processo desafiado. (Amanda, Relatório de Estágio, 2011).

Nos excertos acima, como nos diz Larrosa (1994, p.32), é possível perceber o funcionamento de certos "mecanismos de produção de identidade" - identidade docente. Afirmam o ser docente como uma tarefa que implica a "interrogação sobre sua prática" e a busca pelo "conhecer-se" $e$ "reinventar-se" - indicativos de um modo de atuar como professor e professora, pertencentes a um discurso, que tem suas próprias regras, no qual os/as estagiários/as também se inserem e a partir do qual produzem sua narrativa. Mas é preciso considerar que o sujeito que se julga, se avalia, se narra e que "aprende a dominar-se, governar-se ou conduzir-se" (idem, p. 40) pode, também, encontrar formas outras que o encaminhe a "perceber seus perigos, resistirmos a suas inércias, ensaiar novas formas de subjetivação" (idem, p.42). Não se trata de fugir aos dispositivos produzidos por uma história social e política na qual todos nós nos encontramos, mas, sim, de considerar que não há apenas processos de imposição sobre o sujeito, mas também processos de produção do próprio sujeito. Por isso, a maneira como os/as estagiários/as se percebem como docentes tem, também, uma dimensão de liberdade, de práticas de liberdade. Eles/as podem almejar ser de outro modo, ensaiando outros movimentos de viver e pensar as práticas docentes. A relação do sujeito consigo mesmo abre espaço para um outro modo de existência professor e professora. Para entender esta relação podemos perguntar, juntamente com Larrosa (1994, p.41), sobre o que buscava Foucault ao "romper com as evidências, mostrando a trama de sua fabricação, suas condições de possibilidade, suas servidões [...]? Talvez nos ensinar que nosso olhar é mais livre do que pensamos". 


\section{Considerações Finais}

Este texto nasceu do convite da colega Patrícia Velasco e do colega Benedito de Almeida Junior (Benê) para compor uma mesa de discussão, no encontro do GT Filosofar e Ensinar a Filosofar, na Universidade Federal do Maranhão, em outubro de 2019. $\mathrm{O}$ título que lhe demos foi "O que pensam discentes e docentes sobre formação de professores para o ensino de filosofia?". A partir de então pensei em como seria minha contribuição na resposta à pergunta proposta para a mesa e logo me veio à mente os escritos dos/as estagiários/as, que sempre me afetaram muito e que se acumulam nos meus arquivos pessoais e nas caixas arquivos do Laboratório de Ensino e Aprendizagem de Filosofia, o LEAF. Também era bem presente a bela dissertação de minha orientada, Jéssica Erd Ribas, defendida naquele ano, 2019, que produziu uma genealogia da formação docente no curso de Filosofia da UFSM tomando como materialidade um grande conjunto de projetos e relatórios de Estágio. Ela foi a primeira pessoa a colocar seu interesse de pesquisadora sobre aqueles materiais e reacendeu em mim meu desejo também de fazer o mesmo.

O que pensam os discentes sobre sua formação de professores de filosofia? Esta é a pergunta que me encorajou a seguir o caminho de Jéssica Erd Ribas, dentro dos limites da produção de um texto para nossa mesa. Nos projetos, relatórios e artigos finais estaria a resposta, ponderei. Lá encontraria o que pensam sobre sua formação como futuros/as professores/as de filosofia: críticas, reclamações, alguns elogios, preocupações, angústias. Uma característica desses escritos: sua dimensão pessoal, pois escrevem sobre si mesmos, e não sobre um sujeito anônimo $e$ universal. Escrevem sobre suas frustrações com a docência, suas alegrias; avaliam o que fizeram; abordam temas filosóficos, que consideram vitais, mas que estiveram ausentes do currículo. Lembrei, também, dos encontros/aulas do Estágio, nos quais não era a escrita, mas a fala que se impunha nas rodas de conversa; falar sobre o que fizeram, como avaliavam suas ações no Estágio, como estavam vivendo seu momento de estagiário/a nas escolas públicas de Santa Maria/RS. Era o momento, como diziam, de terapia coletiva; momento de falar e de ser escutado/a. Momento em que, como orientadora, não tinha sempre uma resposta a dar, mas uma ponderação e outras tantas perguntas a fazer.

No movimento de pensar a construção do texto foi, assim, ficando visível, para mim, o meu modo de atuação como orientadora do Estágio em Filosofia; a forma como "conduzo" os/as estagiários a dizer/escrever/pensar sobre a docência em Filosofia, sobre o ensino da Filosofia. Foi, então, que acionei o texto de Jorge Larrosa, Tecnologias do Eu e Educação, como uma referência central para escrever sobre o que dizem os discentes sobre sua formação como professores e professoras de filosofia, mas também sobre as práticas pedagógicas que eu venho colocando em funcionamento. Compreendi, então, com Larrosa (1994), que as disciplinas de Estágio I e II, por mim conduzidas, são um dispositivo pedagógico, cujo objetivo não é transmitir um conteúdo aos estudantes, mas "produzi-los" como sujeitos professores/as, ou melhor, possibilitar que elaborem ou reelaborem de alguma 
forma a relação consigo mesmo. Constituem um dispositivo pedagógico, que a partir de certas práticas, produzem a mediação da experiência de si dos envolvidos, os conduz a falar de si, escrever sobre si, pensar sobre si. Tais práticas são acionadas e conduzidas, neste caso, por mim, a professora responsável pelo Estágio. Neste texto me detive, então, a explorar e a ensaiar a análise de alguns projetos e relatórios de Estágio. Os excertos aqui apresentados não cobrem todo o período dos arquivos do LEAF; a gama de material é muito grande e certamente a pesquisa poderá prosseguir com outros tantos materiais, de diversos períodos que agora ficaram de fora.

Os escritos de estagiários/as foram selecionados e analisados em duas seções: a primeira buscou trazer para análise seus ditos sobre a trajetória formativa. Ao serem conduzidos a pensar, a planejar e a atuar como professores e professoras de Filosofia no ensino médio, a retomada de seu percurso formativo torna-se inevitável. Recuperam suas vivências, avaliam os conhecimentos adquiridos, as práticas de ensino implementadas, analisam a si mesmos como estudantes que estão se tornando professores e professoras. Produzem narrativas sobre sua formação em um sentido de retomada, de recuperação e de análise do vivido, mas também, elaboram histórias de suas vidas, que abrange certamente o período da formação inicial, mas não apenas. "O que narra é o que leva para a frente, apresentando de novo o que viu e do qual conserva um rastro em sua memória. [...]. Ao narrar-se, a pessoa diz o que conserva do que viu de si mesma" (Larrosa, 1994, p. 28). São dois movimentos: narrar o que permanece como rastro em sua memória e narrar-se a si mesmo, ou seja, dizer desses rastros em si mesmo; pensarse a si mesmo; estabelecer uma relação consigo. Abaixo destaco alguns indicativos que emergiram de suas narrativas:

* Reconhecem a aquisição de domínio conceitual na história da filosofia eurocêntrica.

* Fazem críticas à essa formação filosófica. Reivindicam o estudo de outras perspectivas filosóficas e outros temas como: filosofia $e$ gênero; filosofia latino-americana; filosofia afro-brasileira.

* Destacam a pouca presença de conteúdos e disciplinas sobre Educação e Ensino da Filosofia.

A segunda seção deste texto deu centralidade aos ditos dos/as estagiários/as acerca de seus processos de constituição como docentes de filosofia, que estão ancorados em sua formação inicial. No entanto, o destaque é dado, aqui, para a relação que estabelecem consigo mesmos; analisam a si mesmos, pensam a si mesmos, narram a si mesmos como professores e professoras em formação. Ao conduzi-los, durante o Estágio, tomado aqui como um dispositivo pedagógico, para realizarem autorreflexão sobre seu si docente, para se reconhecerem como sujeitos constituindo-se professores $e$ professoras, tenho em mente que busquei criar condições para que pudessem encontrar brechas para produzirem seu modo de vida docente. Permanece, sim, o caráter de assujeitamento produzido no âmbito do dispositivo pedagógico que é o Estágio, mas também de toda a formação. No entanto, eles/as experimentam, no processo de governarem a si mesmos, a possibilidade elaborar uma condução ética e estética de sua 
vida docente e instaurar práticas de liberda-

de.

\section{Referências}

CASTRO, E. Vocabulário Foucault: um percurso pelos seus temas, conceitos e autores. Belo Horizonte: Autêntica, 2009.

CERLETTI, A. Ensino de Filosofia como Problema Filosófico. Belo Horizonte: Autêntica, 2009.

CHIGNOLA, S. Sobre o Dispositivo: Foucault, Agamben e Deleuze. In: Cadernos IHU ideias. Instituto Humanitas Unisinos, n. 214, vol. 12, 2014. Disponíve em: http://www.ihu.unisinos.br/images/stories/cadernos/ideias/214cadernosihuideias.pdf. Acesso em setembro de 2019.

DELEUZE, G. Foucault. São Paulo: Brasiliense, 2006. Tradução Claudia Sant'Anna Martins.

DREYFUS, H.; RABINOW, P. Michel Foucault: uma trajetória filosófica - para além do estruturalismo e da hermenêutica. Apêndice contendo entrevista com Michel Foucault. 2. ed. revista. Rio de Janeiro: Forense Universitária, 2010.

FAVARETTO, C. Notas sobre Ensino de Filosofia. In: ARANTES, Paulo et all. Orgs. Filosofia e seu ensino. Petrópolis: Vozes; São Paulo: EDUC, 1995. P. 77- 85.

FOUCAULT, M. História da Sexualidade 2 - o uso dos prazeres. $13^{\mathrm{a}}$ ed., $2^{\mathrm{a}}$ impressão. Rio de Janeiro: Edições Graal, 2012.

. Sobre a História da Sexualidade. In: FOUCAULT, M. Microfísica do Poder. 26 ed. Rio de Janeiro: Edições Graal, 2008. Tradução Roberto Machado.

Subjetividade e Verdade (1980-1981). In: FOUCAULT, M. Resumo dos Cursos do Collège de France (1970-1982). Rio de Janeiro: Jorge Zahar, 1997.

Tecnologías del yo y otros textos afines. $1^{a}$. Ed. Buenos Aires:Paidós, 2008. Pensamiento Contemporáneo.

LARROSA, J. Tecnologias do Eu e Educação. In; SILVA, Tomaz Tadeu (org.). O Sujeito da Educação. Petrópolis: Vozes, 1994. Disponível em: http://www.grupodec.net.br/wpcontent/uploads/2015/10/TecnologiasdoEuEducacaoLarrossa.pdf. Acesso em agosto de 2019.

MOREY, M. Introdução a Tecnologías del yo y otros textos afines. Barcelona: Ediciones Paidós Ibérica, S.A. I.C.E. de la Unviersidad Autónoma de Barcelona.

PORLÁN, R.; MARTÍN, J. El diario del professor. Sevilla: Díada, 1997.

RIBAS, J. Estágio Curricular Supervisionado em Filosofia e suas Dobras: uma genealogia da formação filosófica na UFSM. Dissertação de Mestrado, PPGE, UFSM, 2019.

VEIGA-NETO, A. Foucault e a Educação. 2. Ed. Belo Horizonte: Autêntica, 2007.

WEIMANN, A. Dispositivo: um solo para a subjetivação. In: Revista Psicologia \& Sociedade; 18 (3): 16-22; set/dez. 2006. 
ZABALZA, M. Diários de Aula: um instrumento de pesquisa e desenvolvimento profissional. Tradução Ernani Rosa. Porto Alegre: Artmed, 2004.

Recebido em: 04/09/2020

Aprovado em: 19/10/2020 